\title{
CLAVES PARA EL BILINGÜISMO
}

\author{
DAN MUNTEANU \\ Universidad de Las Palmas de Gran Canaria
}

Las situaciones en que dos o más lenguas conviven, a veces en territorios pequeños, han sido y siguen siendo muy numerosas. Basta recordar que en la Antigüedad, en una zona relativamente reducida, donde se formó el rumano, había más de trescientos pueblos con una existencia más o menos duradera, que hablaban cada uno su lengua. Y que hoy día se hablan en el mundo unas cinco mil lenguas en menos de doscientos Estados nacionales. $\mathrm{Si}$ estas situaciones conllevan interferencias y transferencias en muchos casos, llegándose, a veces, a situaciones extremas de aparición de nuevas modalidades lingüísticas (pidgins y criollos), por otra parte, se registran numerosas situaciones en que las distintas lenguas coexisten, sin que las influencias mutuas afectaran sus sistemas. Es natural, por tanto, el interés de los especialistas por las variadas facetas del contacto lingüístico. Ya en 1873, Ascoli formulaba de manera científica la idea más antigua de lo que hoy conocemos como la acción del sustrato, adstrato y superestrato. Desde entonces, se ha escrito mucho sobre el bilingüismo y contacto lingüístico, tanto «que hasta las definiciones se nos han quedado imprecisas», como destaca tan acertadamente Manuel Alvar ${ }^{1}$.

En la historia de los estudios sobre el bilingüismo y el contacto lingüístico, existe, sin embargo, un momento crucial, marcado por la obra de Weinreich ${ }^{2}$. Publicado hace casi medio siglo, el libro aportaba, además de datos y conceptos fundamentales tan corrientes actualmente, como el de «interferencia», una nueva concepción sobre el tema. Desde aquel momento hasta hoy, los estudios dedicados a estas cuestiones han ido aumentando de modo impresionante, especialmente los realizados desde la perspectiva

\footnotetext{
1 "Cuestiones de bilingüismo y diglosia en el español», en Manuel Alvar, Maitena Echevarría, Constantino García, Francisco Marsá, El castellano actual en las comunidades bilingües de España, Junta de Castilla y León, 1986, págs. 11-48.

${ }_{2}^{2}$ Languages in contact. Findings and Problems, The Hague, Mouton, 1953.
} 
sociolingüística, en la lingüística mundial y, particularmente, española. Esto último es explicable, si tenemos en cuenta la realidad lingüística de España, que, a su vez, explica el hecho de que la atención de los estudiosos españoles se haya centrado sobre todo en los aspectos concretos y de índole sociolingüística que reviste el problema en las distintas zonas bi- o plurilingües del país ${ }^{3}$.

El reciente libro de Maitena Etxebarria Arostegui ${ }^{4}$, que se añade ahora a esa bibliografía, podría parecer, a primera vista, que sigue la misma línea. Sin embargo, el título engaña, porque la autora no se limita a presentar la situación lingüística de la España actual. Etxebarria intenta poner un poco de orden en las múltiples cuestiones y los variados enfoques que presenta la bibliografía más reciente sobre el contacto lingüístico, expone los diferentes puntos de vista sobre los distintos problemas que analiza, con claridad, objetividad y sentido crítico, sin obviar posiciones contradictorias o polémicas y toma cartas en el asunto, decantándose por un punto de vista $\mathrm{u}$ otro o proponiendo su propia opinión.

Fiel a sus líneas de investigación, Maitena Etxebarria aclara en la «Introducción» el objetivo central del libro: «describir y analizar la situación sociolingüística de las comunidades bilingües de España». Sin embargo, en la economía del libro, este tema ocupa sólo la segunda parte. La primera está dedicada al estudio del bilingüismo individual (con los capítulos: Bilingüismo individual, Tipos de bilingüismo, Medidas de bilingüismo, Formación y desarrollo del individuo bilingüe); y al bilingüismo social, incluida una tipología de las comunidades bilingües del mundo (con los capítulos Bilingüismo social, Comunidades bilingües, La educación bilingüe).

Al tratar la cuestión del bilingüismo individual, la autora pasa revista a la multitud de definiciones del bilingüismo, desde la de Bloomfield hasta las más modernas, como la de J.F. Hamers y M. Blanc, todas basadas, con matizaciones, en la competencia del hablante en las dos lenguas; y se decanta por una definición más compleja, que tiene en cuenta las diferentes facetas del bilingüismo, en la línea de la propuesta de W.F. Mackey:

[...] llamaremos bilingüe al individuo que, además de su propia lengua, posee una competencia semejante en otra lengua y es capaz de usar una $\mathrm{u}$ otra en cualquier situación comunicativa y con una eficacia comunicativa idéntica. Aunque se trata de una situación ideal, ya que en la reali-

\footnotetext{
${ }^{3}$ Recordamos, entre otros títulos, el libro antes mencionado de Manuel Alvar, Maitena Echevarria, Constantino García y Francisco Marsá (véase nota 1), el coordinado por Aurora Juárez Blanquer (Las lenguas románicas españolas tras la Constitución de 1978, Granada, Ediciones Tat, 1988) o el de César Hernández Alonso (Lenguas en contacto y política lingüistica en la España actual, Burgos, Caja de Burgos, 1994).

${ }^{4}$ El bilingüismo en el Estado español, Bilbao, Ediciones FBV, S.L., 1996 [495 págs.].
} 
dad «son individuos que se aproximan más o menos a este ideal, la definición es útil porque nos sirve de punto de referencia respecto del cual valoramos el bilingüismo de un individuo concreto».

El bilingüe definido así tiene presentes sólo las posibilidades del sistema lingüístico que está utilizando en un momento determinado, aunque la autonomía de los dos códigos no es nunca absoluta y total y se producen interferencias. Al producir un texto, el bilingüe introduce, de vez en cuando, en la lengua $\mathrm{A}$ elementos de la lengua $\mathrm{B}$ y viceversa. Cuanto más imperfecto es el bilingüismo de un individuo, tanto más frecuentes son las interferencias entre los dos códigos. Frecuentemente, el individuo bilingüe llega también a la alternancia de códigos.

Otra característica del bilingüe es su capacidad de traducir de una lengua a otra. La autora aborda de paso este aspecto, en un apartado muy breve, que, en nuestra opinión, merecía más espacio. Porque el bilingüe-traductor se encuentra en la situación particular de ser receptor y productor de un texto a la vez. Como receptor tiene que llegar a la intención comunicativa del productor, al plan global del texto; y luego, como productor, textualizar ese plan global que no es suyo, en otra lengua. Según las características del texto, el bilingüe tiene que ser, en estos casos, no sólo bilingüe, sino también «bicultural», a nuestro juicio. Es decir, parafraseando la definición del bilingüe dada por la autora, el traductor debe poseer competencia semejante en los universos culturales, los dominios epistémicos correspondientes a las dos lenguas.

Maitena Etxebarria también plantea el tema del bilingüe bicultural, pero desde otra perspectiva. Al proponer una clasificación en «Tipos de bilingüismo», la fundamenta en sus dimensiones psicológicas. Distingue así el bilingüismo según la relación entre el lenguaje y el pensamiento, según la competencia alcanzada en ambas lenguas, según la edad de adquisición de las dos lenguas, según el estatus sociocultural de las dos lenguas y según la pertenencia y la identidad culturales.

Según la relación lenguaje-pensamiento, Etxebarria considera, junto con S.M. Ervin y C.E. Osgood, que existen bilingües compuestos y coordinados, pero destaca, acertadamente, que la distinción no es absoluta, porque «las diferentes formas de bilingüismo deben situarse en un 'continuum' en el que en un extremo se encontraría el bilingüe compuesto y en el otro el bilingüe coordinado; igualmente, un individuo bilingüe puede ser relativamente compuesto para determinados conceptos y coordinado para otros». Según la competencia lingüística, los bilingües son equilibrados y dominantes. Según la edad de adquisición, la autora distingue entre bilingüismo de infancia o precoz, que puede ser simultáneo (el niño aprende dos lenguas ma- 
ternas a la vez) o consecutivo (el niño adquiere la segunda lengua a una edad muy temprana, pero siempre después de haber adquirido la lengua materna); bilingüismo de adolescencia (la segunda lengua se aprende entre los 10/11 y los 16/17 años); y bilingüismo adulto (la adquisición de la segunda lengua se produce en edades posteriores a las ya mencionadas). Según la pertenencia y la identidad culturales, el bilingüe puede ser bicultural (cuando se identifica con los dos grupos culturales correspondientes a las dos lenguas y es reconocido como tal por los miembros de cada uno de los grupos) y monocultural («cuando mantiene la identidad cultural del grupo al que pertenece»); o también bilingüe aculturado en $\mathrm{L}_{2}$ (cuando renuncia a su identidad cultural y adopta la identidad cultural del grupo que habla la segunda lengua) y bilingüe cultural anómico (cuando no puede «expresar su pertenencia ni su adecuación a ninguna de las dos culturas»).

Nos parece interesante recordar, de paso, en este contexto, el concepto de «comunicación intercultural» propuesto por Zimmermann ${ }^{5}$ y sus estrategias particulares desarrolladas no sólo en el dominio lingüístico-semántico, sino también en otros, como el pragmático-discursivo y el paralingüístico.

En un segundo apartado del mismo capítulo, la autora propone una clasificación del bilingüismo individual según el uso lingüístico (U. Weinreich y W.F. Mackey), que implica la noción de grado de competencia del individuo en cada una de las lenguas. A su vez, ésta depende de las funciones de ambas lenguas, según Mackey. Las funciones de cada una y el grado de competencia de ambas en el bilingüe determinan el paso de una lengua a otra, es decir la alternancia de códigos. El grado, la función y la alternancia determinan las interferencias de una lengua en la otra, que pueden ser culturales, léxicas, gramaticales o fonológicas.

Las funciones de las lenguas en cuestión pueden ser externas (tipos de contacto: la familia, la comunidad, la ecuela, los medios de comunicación de masas, la correspondencia; efectos de entorno: integración social, intercomunicación, comportamiento, función semántica, sistema cultural) e internas (la edad, la aptitud - inteligencia, memoria, actitud, motivación-y la utilización interior de una lengua). Maitena Etxebarria analiza todas esas funciones, así como las variables de las funciones externas: duración, frecuencia, presión.

Después de estudiar los tipos de bilingüismo y el carácter multidimensional del mismo, la autora analiza las medidas del bilingüismo, partiendo del planteamiento moderno que aprecia que el bilingüe no es la suma de dos «es-

\footnotetext{
${ }^{5}$ Klaus Zimmermann, «Prólogo», en Klaus Zimmermann, Christine Bierbach (eds.), Lenguaje y comunicación intercultural, Frankfurt, Vervuert/Madrid, Iberoamericana, 1996, págs. $7-12$.
} 
tados monolingües», sino «que existe una especificidad propia ligada al estado bilingüe». Se estudian las medidas comparativas, los tests de competencia lingüística (en la lengua materna y en la segunda lengua); los tests de comportamiento, como el tiempo de reacción, con la descodificación verbal y la codificación no verbal, la descodificación no verbal y la codificación verbal (Ervin, Macnamara); los tests de asociación verbal (Lambert); los tests de la dimensión compuesto/coordinado; los cuestionarios lingüísticos, las auto-evaluaciones y las evaluaciones de la producción lingüística; la medida de los correlatos cognitivos del bilingüe (con el fin de demostrar la diferencia cognitiva entre el bilingüe y el monolingüe); y la medida de los correlatos afectivos del bilingüe (se analizan los juicios de valor del individuo bilingüe con respecto a las lenguas que utiliza y las personas que las hablan), así como las más importantes técnicas de ésta, como la del «diferencial semántico» (Osgood, Suci y Tanenbaum) y la del matched guise (Lambert, Hodgson, Gardner, Fillembaum) o la de la identidad cultúral del bilingüe.

Las investigaciones sobre el bilingüismo individual implican el estudio del desarrollo cognitivo, lingüístico y neuropsicológico del individuo bilingüe; y con especial atención las implicaciones neuropsicológicas del bilingüismo y sus relaciones con el desarrollo cognitivo y sociocultural del niño. Etxebarria hace un repaso a los estudios dedicados al desarrollo del niño bilingüe (desde los trabajos de pionerato de Ronjat y Leopold, hasta los modernos de Doyle, Champagne y Segalowitz, así como de Swain, Klima, Bellugi, Gregoire o Padilla y Liebman), a sus metodologías y resultados y concluye con moderación y objetividad, que

[...] Es muy probable que una estrategia de aprendizaje única esté en el origen del desarrollo del bilingüe, pero que también el niño desarrolla muy tempranamente determinadas estrategias de diferenciación. También nos parece, quizás, algo prematuro, avanzar la hipótesis de un desarrollo único, o, doble y separado, para el conjunto del desarrollo lingüístico del bilingüe, ya que, todavía, sólo ciertos aspectos lingüísticos y psicolingüísticos específicos del desarrollo bilingüe están analizados.

Dentro de los estudios consagrados al contacto lingüístico, sobre todo desde la perspectiva sociolingüística, en los últimos años se está prestando mucha atención a la «mezcla de códigos» o Code-Switching, concepto entendido como interferencia lingüística en términos de Weinreich, y a los «préstamos adaptados» (préstamos léxicos modificados de acuerdo con el léxico de la lengua que los toma prestados antes de llegar a pertenecer a una determinada categoría gramatical, de tipo chequear < ingl. to check). Estos aspectos son, a juicio de Maitena Etxebarria, particularmente característicos del desarrollo lingüístico en el individuo bilingüe. 
Otra cuestión de sumo interés para el estudio del bilingüismo es el desarrollo neuropsicológico del bilingüe y las relaciones existentes entre el desarrollo del bilingüismo y el desarrollo intelectual: el bilingüismo y el desarrollo cognitivo (relacionado por Maitena Etxebarria con la medida de los correlatos cognitivos del bilingüismo), el contexto sociocultural en el desarrollo del bilingüismo y la edad de adquisición del bilingüismo (con la polémica sobre el período crítico en la adquisición de una segunda lengua, sostenida principalmente por Jakobovits y Oyama).

En relación con el primer aspecto mencionado, Maitena Etxebarria presenta las investigaciones llevadas a cabo con el fin de aportar alguna respuesta a preguntas tan inquietantes como

[...] לhay un desarrollo neuropsicológico distinto en el bilingüe, comparado con el monolingüę?, ¿el bilingüe trata la información en las dos lenguas, de una manera análoga, o, ha desarrollado mecanismos cerebrales específicos en cada una de las lenguas?, ¿la edad de adquisición juega un papel pertinente en la determinación de la dominancia cerebral para una de las lenguas del bilingüe?, ¿el nivel de competencia, alcanzado en la segunda lengua, tiene que ver con la implicación respectiva de los dos hemisferios en el tratamiento de la información verbal presentada?, ¿el contexto de aprendizaje y de exposición a una segunda lengua es pertinente en la determinación de la relación hemisférica? y ¿cuál es el papel de las diferencias estructurales, entre dos lenguas, en la elaboración de la implicación hemisférica respectiva?

La conclusión de la autora es que los estudios realizados hasta la fecha no permiten «destacar un perfil único de funcionamiento cerebral del bilingüe», pero que «la edad del bilingüismo y la experiencia de adquisición de las dos lenguas, en la primera infancia, son factores cruciales en el desarrollo de las preferencias hemisféricas».

Todos los estudiosos están de acuerdo en la actualidad que «no es posible estudiar el bilingüismo en el individuo, sin tener en cuenta la función de las lenguas que usa, en la comunidad a la que pertenece», pone de manifiesto con razón Maitena Etxebarria, al justificar los capítulos dedicados al bilingüismo social en su libro.

Tras analizar las definiciones del bilingüismo social (Siguan, Mackey), la autora delimita el concepto desde su propio punto de vista:

Llamaremos bilingüismo social o colectivo al hecho de que en una sociedad o, en un grupo, o, institución social determinado, se utilicen dos lenguas como medio de comunicación. La existencia de dos lenguas en un mismo contexto social implica que parte de los individuos sean bilingües, aunque el bilingüismo social no depende ni del número de bilingües, ni 
de la intensidad del bilingüismo [...] la descripción de la comunidad bilingüe debe incluir [...] número de hablantes de cada lengua y/o de ambas, prestigio, «status» y funciones de éstas.

$\mathrm{Al}$ analizar las causas del bilingüismo, la autora hace un estudio de los factores extralingüísticos o las razones históricas, sociales y culturales de una situación bilingüe: ocupación o colonización; comercio; superioridad demográfica; poder y prestigio; expansión y ascendencia; educación; influencia económica; religión; medios de difusión. Con respecto a la expansión de una lengua en detrimento de otra, Etxebarria destaca que: «[...] ni la conquista militar, ni el número de hablantes de una lengua determinada son factores, en sí mismos, suficientes, para la expansión; no se trata sólo de estos factores, sino de la 'calidad' de los hablantes que la utilizan». Punto de vista sumamente interesante, que compartimos sin reservas, porque una lengua no se impone sobre otra por la superioridad del sistema lingüístico en sí y/o por su prestigio político y militar como lengua de los conquistadores, sino, como destaca Alleyne ${ }^{6}$, debido el estrato superior que ocupan sus hablantes «en el arreglo jerárquico de las culturas del mundo» en un momento determinado. Si bien muchos etnolingüistas no aceptan este planteamiento, no es éste el lugar apropiado para debatir a fondo la cuestión.

Las dimensiones del bilingüismo son extremadamente variables y repercurten en el individuo, la lengua y la sociedad. De aquí la importancia de su estudio. En el subcapítulo dedicado este tema, Maitena Etxebarria las agrupa en cuatro puntos: distribución o reparto (concentración de bilingües, diseminación, aislamiento o contacto diario); estabilidad (dimensión que depende de las corrientes políticas, sociales, demográficas y de la proximidad de un gran número de hablantes monolingües en una comunidad bilingüe); función o empleo del bilingüismo por parte de los individuos bilingües; e interdependencia (la proporción de la interpenetración de las dos lenguas).

El apartado consagrado a las medidas del bilingüismo social parte de una realidad que la misma autora reconoce: «No existe una metodología propia y única diseñada para el estudio del contacto de lenguas y, además, existen pocos instrumentos de medida desarrollados con la finalidad específica de cuantificar los problemas del bilingüismo colectivo». Ante esta situación, la autora analiza las distintas medidas del bilingüismo colectivo y

\footnotetext{
${ }^{6}$ Mervyn C. Alleyne, «Acculturation and the Cultural Matrix of Creolization», en Dell Hymes (ed.), Pidginization and Creolization of Languages. Proceedings of a Conference held at the University of the West Indies, Mona Jamaica, April 1968, Cambridge, University Press, págs. 169-186.
} 
los diferentes enfoques de las mismas, desde la aproximación macro-sociológica a la aproximación micro-sociológica (que estudia pequeñas comunidades bilingües con técnicas propias de la antropología).

En el nivel macro-sociológico, las principales técnicas de recogida de datos (censos y encuestas sobre el comportamiento lingüístico) y la interpretación de éstos son problemáticos, en la opinión de la autora, porque pueden crear divisiones arbitrarias en una comunidad lingüística, no ofrecen informaciones sobre minorías lingüísticas repartidas entre dos o varios países, los cuestionarios varían de un país a otro y, de acuerdo con la claridad mayor o menor de las preguntas, las respuestas pueden variar mucho. En base a los censos se pueden realizar diferentes medidas del bilingüismo colectivo. La autora presenta las siguientes: de la tasa de asimilación de una comunidad (Roy); de la diversividad lingüística (Greenberg, Lieberson); del comportamiento lingüístico, basado en encuestas de distintos tipos: encuestas geolingüísticas, atlas lingüísticos, estudios etnolingüísticos, como los llevados a cabo en Honduras y Nicaragua (Reyburn), Filipinas (Sibayan) o África Oriental (Whiteley), estudios realizados por comisiones de encuesta en países multilingües (como las del Canadá) y sondeos lingüísticos con muestras aleatorias, que se basan en un número reducido de comportamientos específicos.

Los tipos de comunidades en que se hablan dos lenguas se establecen de acuerdo con las relaciones lingüísticas existentes en una comunidad bilingüe. Se distinguen así, según Etxebarria, tres tipos: a) los dos grupos están distribuidos territorialmente y sus lenguas poseen un estatus oficial igual en cada uno de los territorios (el Canadá, Bélgica, Suiza); b) junto a las lenguas autóctonas propias de grupos étnicos o Estados, se utiliza(n) otra(s) lengua(s) grande(s) de comunicación hablada(s) por un número variable de hablantes de cada grupo (África Oriental, la ex Unión Soviética); c) las dos lenguas son habladas por una parte variable de la población, pero están en distribución de uso complementario en la comunidad bilingüe (el Paraguay: guaraní y español; Haití: criollo y francés). Relacionado con este aspecto, no carece de interés el caso particular de los monolingües que viven en una comunidad bilingüe y el comportamiento de los individuos bilingües.

Etxebarria analiza el papel de la lengua en las relaciones entre los grupos y la lengua como símbolo de la identidad étnica de un grupo, que, como es sabido, puede ser un fuerte obstáculo a la influencia ejercida por las lenguas con estatus dominante en una situación de contacto lingüístico. No obstante, para que una lengua sea identificada con la etnicidad, tiene que ser percibida como un «valor central» en la cultura de un grupo. En el apartado sobre este tema, la autora analiza varios casos concretos de comu- 
nidades bilingües con relaciones etnolingüísticas muy complejas, que varían debido a factores extralingüísticos y cuya valoración sobre la lengua pudo cambiar en determinas circunstancias. Otro apartado lo dedica al estudio de la vitalidad etnolingüística, y presenta el modelo probabilístico de Giles, Bourhis y Taylor.

En un subcapítulo aparte, Maitena Etxebarria presenta también diferentes modelos de identidad colectiva en función de la lengua, según las propuestas de Ross y Taylor y Giles: comunal, minoritaria y nacional. En cuanto al papel de la lengua en la movilización étnica, distingue «cuatro formas de manipular una lengua»: revivir una lengua ancestral, o convertir una modalidad en lengua nacional; la defensa de una lengua que el grupo considera amenazada, acompañada frecuentemente por una «purificación» de la misma; utilización de la lengua dominante por los otros grupos étnicos, para «hacerse oír»; redefinir la lengua y las características del grupo (el caso de los afroamericanos en los EE.UU., o de los afroantillanos en Gran Bretaña). El examen de las relaciones entre diversos grupos y las lenguas a nivel nacional, está estrechamente vinculado a los problemas de la planificación lingüística, con sus dos aspectos, interno y externo. En este apartado, la autora examina también algunas de las soluciones aportadas por la planificación lingúística en algunos casos de sociedades multilingües, desde el Canadá o Bélgica, hasta los países africanos, donde se recurre a menudo a una «lingua franca» o al «nacionismo» (cuando falta una tendencia interna unificadora).

Otro tema interesante es el estatus de las lenguas en contacto y los fenómenos de variación o estratificación sociolingüística. Maitena Etxebarria estudia los conceptos de diglosia, de language shift o desplazamiento lingüístico y el nacimiento de una nueva modalidad lingüística (pidgin) a raíz del contacto, con posibilidades de convertirse en lengua de toda una comunidad en determinadas circunstancias. La autora comenta el concepto de diglosia (Ferguson), ampliado por Gumperez para las comunidades plurilingües, y de dinomia (Saville-Troyke), como equivalente étnico-cultural de la diglosia. En este contexto estudia también varias situaciones concretas como las de la India, Bélgica, Luxemburgo o América latina. En cuanto al desplazamiento lingüístico, Etxebarria señala los tipos de factores que facilitan el proceso (cambio en el modo de vida de un grupo, cambios en la correlación de fuerzas entre los grupos, actitudes desvalorizadoras hacia la lengua de un grupo, combinación de algunos de estos factores) y analiza algunos casos concretos.

El nacimiento de una nueva modalidad lingüística como resultado del contacto de lenguas, conocido como pidginización y/o criollización, y el 
proceso inverso de descriollización, es uno de los temas más candentes en la lingüística actual. Maitena Etxebarria presenta en su libro sucintamente las condiciones de la aparición del pidgin y sus rasgos principales (simplificación de la forma externa del lenguaje, reducción de la forma interna y reducción de las funciones y los dominios de empleo); y delimita el concepto de otros tipos de habla que no poseen todas las características del pidgin, como «lingua franca», «sabir» o «pseudo-sabir». No obstante, no entra en los detalles de la evolución de los pidgins (pre-pidgin, expandido, estabilizado, elaborado, etc.). En cuanto a las principales teorías que explican la aparición de una nueva lengua, la autora menciona a las siguientes:

a) Reducción y simplificación de la lengua base por parte de los hablantes nativos (Bloomfield), hipótesis en que se basa Hall Jr. en su teoría poligenética. Citando a Ferguson y DeBose, Etxbarria aprecia que «no se trata de una simplificación deliberada, sino más bien de un uso de factores prescritos a través de las conveniencias de una comunidad lingüística». Nos parece interesante recordar, sin embargo, que muchos criollistas consideran que se trata de una simplificación consciente por parte del hablante de la lengua base, con el fin de facilitar la comprensión, aunque, a veces, esa simplificación se produce también de forma inconsciente. De hecho, esta simplificación tiene varias facetas, generadas por causas diferentes: la situación periférica (Malmberg); la adopción de palabras de la lengua base sin su flexión original (a causa del desconocimiento o conocimiento imperfecto de la lengua prestadora); y la aplicación de estrategias para alivianar la tarea cognitiva que implica el manejo de dos códigos.

b) Interferencia, entendida como modificación profunda de la lengua por los hablantes, una vez interrumpido el contacto con los hablantes de la lengua base. Según Zimmermann (loc. cit.), se trata de estrategias desarrolladas en las condiciones particulares de la comunicación intercultural. La autora considera, citando a Alleyne, que «Las semejanzas morfosintácticas entre los 'pidgin' procedentes de lenguas-base diferentes se explican por la superposición de estructuras sintácticas de lenguas-sustrato». En nuestra opinión, son necesarias algunas matizaciones: en primer lugar, las lenguas participantes en el nacimiento de una nueva modalidad no tienen la misma posición en el proceso de génesis, no existe igualdad de fuerzas entre las mismas, y es la lengua dominante (base) la que impone, generalmente, sus propias tendencias internas de evolución a todo el proceso; en segundo lugar, la lengua dominante acepta y adopta elementos de la(s) otra(s) lengua(s) sólo en la medida en que éstos no son completamente ajenos a su organización interna o cuando consolidan 
sus propias tendencias de desarrollo (Jakobson, Weinreich, Silva-Corvalán ${ }^{7} \mathrm{y}$ otros).

c) Reestructuración, debida a las estrategias universales del lenguaje (Traugott, Bickerton). Esta teoría, defendida por Bickerton para los criollos, tiene una aceptación limitada, actualmente, por lo menos entre los criollistas.

Además de estas teorías, no carece de interés recordar, en este contexto, la hipótesis aplicable a varios criollos, según la cual el proceso de criollización no sería una evolución hacia una lengua meta, sino desde varias lenguas fuente (Maurer ${ }^{8}$ ). Así como la teoría del papel de la comunicación intercultural, más exactamente de los posibles sincretismos que se producen en la mente de los hablantes en contacto con la lengua base y su universo cultural. Sincretismos que, a veces, se reflejan en los criollos en estructruras superficiales mixtas ${ }^{9}$.

La condición fundamental del nacimiento de un criollo, subraya acertadamente Etxebarria, es que el pidgin se convierta en lengua materna y, ulteriormente, desarrolle también otras funciones, además de las de lengua materna. Habría que añadir que, generalmente, esas funciones las desarrolla la misma comunidad criollohablante, mediante esfuerzos conscientes, como lo demuestran el caso del criollo de Haití y, particularmente, el caso del papiamento, que se ha convertido en lengua de cultura, literatura, de la prensa escrita y audio-visual y, últimamente, en lengua de instrucción básica. Evidentemente, la génesis del criollo es un proceso más complicado. Las condiciones necesarias para su desarrollo y cristalización están expuestas brillantemente en las obras de Weinreich ${ }^{10}$ y Sankoff ${ }^{11}$.

${ }^{7}$ Roman Jakobson, «Sur la théorie des affinités phonologiques des langues», en Actes $d u$ Quatrième Congrès International des Linguistes tenu à Copenhague du 27 août au $1^{\text {er }}$ septembre 1936, Copenhague, 1938, págs. 48-59; Carmen Silva-Corvalán, «Spanish Language Attrition in a Contact Situation with English», en H.W. Seliger, R. Vago (eds.), First Language Attrition: Structural and Theoretical Perspectives, Cambridge, University Press, 1991, págs. 151-171; «El español actual en Estados Unidos», en César Hernández López (ed.), Historia y presente del español de América, Junta de Castilla y León, 1992, págs. 827-856; «Cambios sintácticos en situaciones de contacto lingüístico», en Actas del X Congreso Internacional de la Asociación de Lingüistica y Filología de la América Latina, Veracruz, 11-16 de abril de 1993, México, 1996, págs. 302-308, Manuel J. Gutiérrez, Carmen Silva-Corvalán, «Clíticos del español en una situación de contacto», REL 23/2, 1993, págs. 207-220.

${ }^{8}$ Philippe Maurer, "Le papiamento de Curaçao: un cas de créolisation atypique?», Études créoles IX, 1986, págs. 97-113.

${ }^{9}$ Dan Munteanu, El papiamento, lengua criolla hispánica, Madrid, Gredos, 1996; «La relación intención comunicativa-textualización en la génesis de los criollós», en Actas del $2 .^{\circ}$ Coloquio Internacional sobre lenguas criollas de base española y portuguesa, Berlín, 7-11 de octubre 1996, Berlín, Instituto Ibero-Americano [en prensa].

${ }^{10}$ Op. cit., págs. 104 y sigs.

11 Gillien Sankoff, "Variation, Pidgins and Creoles», en Albert Valdman, Arnold Highfield (eds.), Theoretical Orientations in Creole Studies, Nueva York, Academic Press, 1980, págs. 139-164. 
Maitena Etxebarria define la descriollización, junto con De Camp, como un proceso de evolución del criollo hacia la lengua estándar, que conlleva la desaparición paulatina de las diferencias entre el criollo y la lengua estándar. En este contexto hubiera sido interesante, quizás, recordar, aunque brevemente, algunos casos de descriollización, las situaciones especiales en que la lengua base del criollo no es la lengua oficial (el chabacano, el papiamento), el concepto de lengua mixta, ampliado y profundizado en estudios recientes, el concepto de semi-criollo $\left(\mathrm{Holm}^{12}\right.$ ) y el concepto de anticriollo (Couto ${ }^{13}$ ), definido como una lengua o variedad lingüística con una gramática de la lengua dominante o de superestrato y un léxico procedente total o parcialmente de la(s) lengua(s) minoritaria(s) o de substrato.

A modo de conclusión, la autora delimita la competencia lingüística que «mejor da cuenta de la realidad compleja de la alternancia de códigos», considerando, en la línea de Lipski, que el bilingüe

[...] debe poseer la capacidad de comparar, mentalmente, frases equivalentes en las dos lenguas, debe poder evaluar el grado de equivalencia sintáctica y debe también operar con la alternancia sólo en aquellos casos en los que la equivalencia está preservada [...] un mecanismo de comparación capaz de yuxtaponer los dos sistemas simultáneamente y activar la alternancia de códigos en aquellos puntos precisos y posibles de la frase $\mathrm{y}$ el discurso.

La autora analiza también la definición y la tipología de la educación bilingüe, sus factores y componentes (socio-históricos, socio-estructurales, socio-psicológicos) y los programas de educación bilingüe. Este apartado final presenta las experiencias de «inmersión», las críticas a la misma, los tipos de inmersión (precoz total, precoz parcial, tardía), así como las conclusiones a las que han llegado los investigadores de los programas de inmersión. Y termina con la presentación de los programas de educación bilingüe en Irlanda y el País de Gales.

La cuestión del bilingüismo en España, como indica el título del libro que comentamos, es, en realidad, sólo el tema de la segunda parte del libro de Etxebarria, titulada «Las comunidades bilingües de España», que ocupa poco más de la mitad del volumen. Se presenta la configuración de las comunidades autónomas con lengua propia, el marco legal en materia lingüís-

\footnotetext{
12 John Holm, «Popular Brazilian Portuguese: a semi-creole», ponencia presentada en el Coloquio sobre criollos de base léxica portuguesa, Lisboa, 1991; «American Black English and Afrikaans: two semi-creoles», comunicación presentada en el Simposio de la Society for Pidgin and Creole Linguistics, Chicago, del 3 al 6 de enero de 1991.

${ }^{13}$ Hildo Honório do Couto, Introdução ao estudo das línguas crioulas e pidgins, Brasilía, Editora Universidad de Brasilía, 1996.
} 
tica de éstas y las comunidades en situación de diversidad lingüística que contemplan legalmente la protección de la lengua (Valle de Arán, Aragón, Principado de Asturias). Los capítulos dedicados al catalán, gallego, vasco tienen la misma estructura: caracterización general: datos morfológicos, demográficos y estructura política; norma lingüística y variedades; marco legal; situación sociolingüística: conocimiento y uso; la lengua en la administración; en la enseñanza; en los medios de comunicación social y en la producción cultural. El subcapítulo dedicado a la situación sociolingüística del vasco, dominio ampliamente estudiado por Etxebarria, trata también sobre la competencia lingüística, la lengua materna y la hablada en casa por los vascuences, mientras el subcapítulo sobre el vasco en la enseñanza se ocupa de los modelos de enseñanza bilingüe en el País Vasco y su evolución, la difusión de la enseñanza bilingüe y la enseñanza universitaria y el euskera.

Completan este amplio y detallado panorama de la situación lingüística en España, los capítulos dedicados a las Islas Baleares, Valencia y Navarra, que tienen, con pequeñas modificaciones debidas a cada realidad concreta, la misma estructura que los anteriores. La autora aporta información riquísima, datos estadísticos y gráficas muy interesantes y útiles sobre el número de hablantes de cada lengua, cúantos habitantes de cada comunidad hablan la respectiva lengua, cuántos la entienden y cuántos la escriben, el conocimiento de la lengua según la edad, la evolución de la competencia lingüística, las horas de clase en la respectiva lengua, la distribución de los alumnos en la enseñanza primaria por lenguas, etc., que hacen que esta segunda parte del libro no se limite a ser un pretexto para la primera, sino un estudio en sí mismo, de inapreciable utilidad no sólo para los especialistas, sino para cualquier persona deseosa de informarse sobre la situación lingüística de España.

El libro de Maitena Etxebarria es un título de referencia obligada en la bibliografía de especialidad. La gran sabiduría de la autora, la objetividad, el criterio crítico, pero rigurosamente científico, el método y la riqueza de información son las excelencias de este libro, un estudio serio y amplio de todos los problemas teóricos planteados por el bilingüismo, enfocados desde una perspectiva moderna. 